\title{
Clinicopathological characteristics and treatment outcomes of 162 Chinese patients with metastatic bladder cancer: results from a tertiary teaching hospital
}

\author{
Dechao Feng ${ }^{\#}$, Yunjin Bai ${ }^{\sharp}$, Yubo Yang^, Ping Han^, Wuran Wei^ \\ Department of Urology, Institute of Urology, West China Hospital, Sichuan University, Chengdu, China \\ Contributions: (I) Conception and design: D Feng, P Han; (II) Administrative support: P Han, W Wei; (III) Provision of study materials or patients: \\ D Feng, Y Bai, Y Yang; (IV) Collection and assembly of data: D Feng, Y Bai, Y Yang; (V) Data analysis and interpretation: D Feng, Y Bai; (VI) \\ Manuscript writing: All authors; (VII) Final approval of manuscript: All authors. \\ "These authors contributed equally to this work. \\ Correspondence to: Ping Han, PhD; Wuran Wei, PhD. Department of Urology, Institute of Urology, West China Hospital, Sichuan University, \\ Guoxue Xiang \#37, Chengdu, 610041, China. Email: hanpingwch@163.com; weiwuranwch@126.com.
}

\begin{abstract}
Background: To explore the relationship between clinicopathological features and prognosis of metastatic bladder cancer (MBC) patients in the real world, and to provide peculiar data support for the management of such patients.

Methods: A retrospective analysis of $162 \mathrm{MBC}$ patients who underwent radical cystectomy (RC) in West China Hospital, Sichuan University from September 2010 to December 2015 was conducted. The study included the clinical, pathological and metastatic features of these patients. Chi-square test, Kaplan-Meier method and Cox proportional hazard model were used to assess the relationship between clinicopathological factors and outcomes.

Results: Of the 162 patients enrolled, 137 (84.6\%) were male and 25 (15.4\%) were female. The ages at which the tumors metastasize for men and women were 64.8 \pm 9.4 and $66.2 \pm 12.7$ years, respectively $(\mathrm{P}=0.52)$. The median follow-up time was 13.6 months (IQR: 5.8-33.1 months). Smoking history, pathological stages, and marginal status were independent predictors of the metastasis-free interval (MFI); Pathological stages, local recurrence, liver metastasis, and surgical approaches were significantly associated with cancer-specific survival (CSS) and overall survival (OS). Besides, OS was associated with lymphovascular invasion (LVI) and age at metastasis.

Conclusions: Our study suggests that tumors in MBC patients with a smoking history, positive margins, pT3 or more advanced tumors are more likely to metastasize. Besides, patients with a minimally invasive surgery, local recurrence, and liver metastases are at greater risk of death from bladder cancer; Taken together, our study provides data support for an optimal management of patients with MBC in current realworld practice.
\end{abstract}

Keywords: Bladder cancer; lymph node metastasis (LNM); visceral metastasis; prognosis

Submitted Jan 26, 2020. Accepted for publication Jul 03, 2020.

doi: $10.21037 /$ tcr-20-737

View this article at: http://dx.doi.org/10.21037/tcr-20-737

^ORCID: Dechao Feng, 0000-0002-8267-9920; Yunjin Bai, 0000-0001-6005-6725; Yubo Yang, 0000-0002-0189-3256; Wuran Wei, 00000002-2348-8593; Ping Han, 0000-0002-9710-0037. 


\section{Introduction}

Bladder cancer is one of the most common malignant tumors of the genitourinary system, remaining the 10th most common cancer worldwide, with an estimated 549,000 new cases and 200,000 deaths each year (1). Although the incidence of bladder cancer in China is much lower than that in western developed countries, it has increased year by year in both urban and rural areas, regardless of gender (2). Therefore, enough attention should be paid to bladder cancer.

Half of the patients encounter muscle-invasive bladder cancer (MIBC) relapse after radical cystectomy (RC), in which distant metastasis accounts for $70 \%$ (3). Besides, only about $5 \%$ of metastatic cancer patients survive for at least 5 years post-diagnosis (4). Thus, metastasis is one of the most important causes of death from bladder cancer.

There is currently no cure for metastatic bladder cancer (MBC), whose prognosis is much worse than that of kidney cancer and prostate cancer (1), and the prognosis varies greatly. Currently, the relationship between clinicopathological features and $\mathrm{MBC}$ is unclear. Thus, it is essential to identify the clinicopathological factors associated with metastasis and their impact on prognosis, thereby helping clinicians communicate with patients and implement decision-making. We present the following article in accordance with the STROBE reporting checklist (available at http://dx.doi.org/10.21037/tcr-20-737).

\section{Methods}

\section{Study design}

The study was conducted in accordance with the Declaration of Helsinki (as revised in 2013). The study and disclaimer of informed consent were approved by the West China Hospital of Sichuan University Biomedical Research Ethics Committee (No. 2020366). A retrospective analysis of 420 patients who underwent RC in West China Hospital, Sichuan University from September 2010 to December 2015 was conducted. There were 172 cases of lymph node metastasis (LNM) or visceral metastasis diagnosed by histopathological or radiological examinations, including 9 cases with prostate cancer and 1 with rectal cancer; so, 162 patients were finally included in the statistical analysis. The clinical features included age, gender, smoking history, preoperative abdominal computed tomography (CT) or magnetic resonance imaging (MRI), adjuvant chemotherapy, surgical procedures, local treatment of metastases, metastasectomy, treatment types of metastases, and post-metastasis chemotherapy regimens. Adjuvant chemotherapy was defined as treatment given within 3 months after surgery. The pathological characteristics of primary tumor included pathological stage, grade, tumor size, growth pattern, pathological types, location, marginal status, and whether or not carcinoma in situ (CIS) and lymphovascular invasion (LVI) were combined. The metastatic characteristics included types of metastasis, local recurrence, LNM, numbers of removed lymph nodes, number of positive lymph nodes, bilaterality of positive lymph node, lymph node density (LND), and location or number of visceral metastases. LND was defined as the percentage of metastatic lymph nodes and the total number of lymph nodes removed, i.e., the detection rate of positive lymph nodes. Metastasis within 2 months was synchronous, otherwise it was metachronous. The TNM staging system of 2009 Union for International Cancer Control (UICC) was used for pathological stage and the World Health Organization (WHO) 2004 classification method was used for histological grade. The outcomes included metastasis-free interval (MFI), cancer-specific survival (CSS) and overall survival (OS). MFI was defined as the interval from the diagnosis of bladder cancer to the determination of the first metastatic lesion. OS was defined as the time from the onset of the metastasis to the death of any cause or last follow-up. CSS was defined as the time from the onset of metastasis to death from bladder cancer or last follow-up. All patients underwent abdominal and pelvic CT or MRI before surgery. Besides, they underwent chest X-ray or CT, abdominal and pelvic CT every 3 to 6 months within 2-3 years after surgery and every 6-12 months thereafter. A bone scan and a head CT or MRI were performed only when symptoms occurred.

\section{Pathological assessment}

All pathological specimens were evaluated by the pathology department of West China Hospital, Sichuan University, but the prognoses of the patients were not known.

\section{Statistical methods}

The Kaplan-Meier method was used to evaluate CSS, MFI, and OS. The duration of follow-up was calculated from the date of surgery to the date of death or last followup. Univariate and multivariate Cox proportional hazards 
models were used to assess the clinicopathological features associated with metastasis and prognosis. A multivariate model was constructed using forward stepwise regression (Forward: LR) based on maximum likelihood estimation, where the $\mathrm{P}$ value of the variable entering the model set was 0.05 , and the $\mathrm{P}$ value of the variable culling model set was 0.1 . The Schoenfeld residual trend test was used to validate the Cox proportional hazard assumption. Chi-square test was used to estimate clinical and pathological factors associated with LNM and visceral metastasis. All reported $P$ values were bilateral and statistically significant at $\mathrm{P}<0.05$. Pairwise comparisons of chi-square tests used Bonferroni to correct significant levels. All statistical analyses were accomplished by the software .

\section{Results}

\section{Clinicopathologic characteristics}

The clinicopathological features of the 162 patients included in the study were summarized in Table 1. Of the 162 patients, $137(84.6 \%)$ were male and 25 (15.4\%) were female. The ages of diagnosis for men and women were $63.7 \pm 9.5$ and $64.8 \pm 13.3$, respectively $(\mathrm{P}=0.63)$. The ages at which metastasis occurred in men and women were $64.8 \pm 9.4$ and $66.2 \pm 12.7$, respectively $(\mathrm{P}=0.52)$. The mean

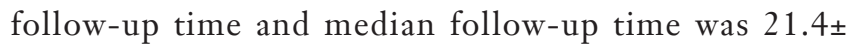
19.9 months (range, 0.3-93.8 months) and 13.6 months (IQR: 5.8-33.1 months). Additionally, factors associated with LNM and visceral metastasis were shown in Tables $S 1, S 2$, separately.

\section{MFI}

The relationship between clinicopathological factors and MFI was summarized in Table 2. The average time from diagnosis to metastasis was 13.8 months (median time: 5.2 months; IQR: 0.9-18.4 months). Notably, adenocarcinoma may be an independent predictor of MFI ( $\mathrm{P}=0.05)$.

\section{CSS and OS}

The average time to CSS and OS was 35.2 and 33.6 months, respectively. The CSS and OS rates of this cohort were shown in Figure 1. The estimated CSS rates [standard error (SE)] at 1, 3, and 5 years were $69 \%(4.3 \%)$, $38 \%(5.0 \%)$, and $20 \%(6 \%)$, singly. The characteristics and corresponding HRs that were significantly associated with CSS and OS were summarized in Table 3. Besides, the univariate analyses of clinicopathological factors associated with MFI, CSS and OS were summarized (https://cdn. amegroups.cn/static/application/e9aa8f6cc613c010ef51e9 92ad8f7b42/tcr-20-737-1.pdf).

\section{Discussion}

Bladder cancer is a common malignant tumor of the urinary system, and its metastasis is one of the most important causes of death. Despite advances in its treatment, there has been little improvement in survival for patients with MBC over the last 2 decades (4). Currently, little research has been done on the risk factors associated with organ metastasis. Our purpose is to clarify the clinicopathological factors associated with metastasis and prognosis to optimize clinical management.

Similar to previous studies $(5,6)$, our study shows that the most common metastatic site for MBC is lymph nodes, followed by lung, bone and liver. Xie et al. (5) believe that the MFI of bladder urothelial carcinoma (UC) is only significantly associated with the grade of primary tumor and local recurrence. Surprisingly, local recurrence is a favorable factor for MFI. They suppose that recurrence and metastasis are two biological behaviors of UC. During a certain period of time, the malignant tumor and the host are in an equilibrium. However, surgical resection may rebalance the residual cancer cells by recurrence or metastasis. Therefore, once local recurrence has occurred successfully, the transfer time may be delayed. Besides, MFI becomes shorter as tumor grade increases $(5,7)$. However, our results suggest that tumor grade is not a predictor of MFI in MBC, probably due to a small sample size of low-Grade cases (only 10). Based on traditional transfer theory (8), tissue infiltration is an important step in the metastatic process. Our study suggests that bladder cancer with an advanced pathological stage is more likely to metastasize. In addition, we also find that smoking history and positive margins are risk factors for MFI.

In this study, we noted that tumors in some (4/162) patients with superficial low-grade bladder cancer did not develop to MIBC and metastasized directly, similar to previous studies $(5,9)$. These phenomena suggested that more attention and consideration should be given to the treatment of early staged bladder cancer, and more researches are needed to clarify the metastasis mechanism of such patients. 
Table 1 The clinicopathological features of the metastatic bladder cancer patients.

\begin{tabular}{|c|c|}
\hline Features & Data \\
\hline \multicolumn{2}{|l|}{ Clinical features } \\
\hline \multicolumn{2}{|l|}{ Median age, year (IQR) } \\
\hline Age at diagnosis & $64.8(58.4-69.8)$ \\
\hline Age at metastasis & $66.6(60.0-71.4)$ \\
\hline \multicolumn{2}{|l|}{ Gender } \\
\hline Male & $137(84.6 \%)$ \\
\hline Female & $25(15.4 \%)$ \\
\hline \multicolumn{2}{|l|}{ Smoking history } \\
\hline Yes & $74(45.7 \%)$ \\
\hline No & $88(54.3 \%)$ \\
\hline \multicolumn{2}{|l|}{ Abdominal CT or MRI } \\
\hline Negative & $78(55.3 \%)$ \\
\hline Enlarged lymph node & $31(22 \%)$ \\
\hline visceral metastasis & $48(34 \%)$ \\
\hline \multicolumn{2}{|l|}{ Adjuvant therapy } \\
\hline Yes & $33(20.4 \%)$ \\
\hline No & $129(79.6 \%)$ \\
\hline \multicolumn{2}{|l|}{ Metastases treatment } \\
\hline Yes & $113(69.8 \%)$ \\
\hline No & $49(30.2 \%)$ \\
\hline \multicolumn{2}{|l|}{ Surgical approach } \\
\hline Open & $130(80.2 \%)$ \\
\hline Laparoscopic & $29(17.9 \%)$ \\
\hline Robot-assisted & $3(1.9 \%)$ \\
\hline \multicolumn{2}{|c|}{ Treatment regimens for metastases } \\
\hline GP & $19(46.3 \%)$ \\
\hline Gemox & $9(22.0 \%)$ \\
\hline M-VAC & $1(2.4 \%)$ \\
\hline TS & $4(9.8 \%)$ \\
\hline TP & $3(7.3 \%)$ \\
\hline TC & $2(4.9 \%)$ \\
\hline Apatinib & $1(2.4 \%)$ \\
\hline GA & $2(4.9 \%)$ \\
\hline GTC & 2 (4.9\%) \\
\hline
\end{tabular}

Table 1 (Continued)
Table 1 (Continued)

\begin{tabular}{|c|c|}
\hline Features & Data \\
\hline Other chemotherapy regimens & $13(31.7 \%)$ \\
\hline Radiotherapy & $9(22.0 \%)$ \\
\hline \multicolumn{2}{|l|}{ Pathological features } \\
\hline \multicolumn{2}{|l|}{ Size (cm) } \\
\hline Mean \pm SD (range) & $3.73 \pm 1.72(1-10)$ \\
\hline median (IQR) & $3.70(2.5-5.0)$ \\
\hline \multicolumn{2}{|l|}{ Type of size } \\
\hline$<3 \mathrm{~cm}$ & $50(30.9 \%)$ \\
\hline$\geq 3 \mathrm{~cm}$ & $112(69.1 \%)$ \\
\hline \multicolumn{2}{|l|}{ Growth pattern } \\
\hline Single & $44(27.2 \%)$ \\
\hline Multifocal & $118(72.8 \%)$ \\
\hline \multicolumn{2}{|l|}{ Grade } \\
\hline $\mathrm{G} 1 / 2$ & $10(6.2 \%)$ \\
\hline G3 & $152(93.8 \%)$ \\
\hline \multicolumn{2}{|l|}{ Pathological stage } \\
\hline $\mathrm{PTa} / 1$ & $11(6.8 \%)$ \\
\hline PT2 & $28(17.3 \%)$ \\
\hline PT3 & $60(37 \%)$ \\
\hline PT4 & $63(38.9 \%)$ \\
\hline \multicolumn{2}{|l|}{$\mathrm{CIS}$} \\
\hline Yes & $4(2.5 \%)$ \\
\hline No & $158(97.5 \%)$ \\
\hline \multicolumn{2}{|l|}{ LVI } \\
\hline Positive & $46(28.4 \%)$ \\
\hline Negative & $116(71.6 \%)$ \\
\hline \multicolumn{2}{|l|}{ Types of cancer } \\
\hline Urothelial carcinoma & $158(97.5 \%)$ \\
\hline Adenocarcinoma & $34(21 \%)$ \\
\hline Squamous cell carcinoma & $23(14.2 \%)$ \\
\hline Sarcomatoid carcinoma & $4(2.5 \%)$ \\
\hline Others & $2(1.2 \%)$ \\
\hline \multicolumn{2}{|l|}{ Margin status } \\
\hline Negative & $135(83.3 \%)$ \\
\hline
\end{tabular}

Table 1 (Continued) 
Table 1 (Continued)

\begin{tabular}{|c|c|}
\hline Features & Data \\
\hline Positive & $27(16.7 \%)$ \\
\hline \multicolumn{2}{|l|}{ Location } \\
\hline Lateral wall & $96(59.3 \%)$ \\
\hline Posterior wall & $35(21.6 \%)$ \\
\hline Anterior wall & $27(16.7 \%)$ \\
\hline Trigone & $72(44.4 \%)$ \\
\hline Dome & $17(10.5 \%)$ \\
\hline bladder neck & $16(9.9 \%)$ \\
\hline \multicolumn{2}{|l|}{ Metastatic features } \\
\hline Synchronous & $62(38.3 \%)$ \\
\hline Metachronous & $100(61.7 \%)$ \\
\hline \multicolumn{2}{|l|}{ Local recurrence } \\
\hline Yes & $56(34.6 \%)$ \\
\hline No & $106(65.4 \%)$ \\
\hline Lymph node metastasis & $94(58 \%)$ \\
\hline Only lymph node metastasis & $18(11.1 \%)$ \\
\hline \multicolumn{2}{|l|}{ Visceral metastasis } \\
\hline Lung & $53(32.7 \%)$ \\
\hline Bone & $33(20.4 \%)$ \\
\hline Liver & $39(24.1 \%)$ \\
\hline Prostate & $37(22.8 \%)$ \\
\hline Brain & $3(1.9 \%)$ \\
\hline Others & $81(50 \%)$ \\
\hline \multicolumn{2}{|l|}{ Number of visceral metastasis } \\
\hline 0 & $15(9.3 \%)$ \\
\hline 1 & $69(42.6 \%)$ \\
\hline 2 & $44(27.2 \%)$ \\
\hline$\geq 3$ & $34(21 \%)$ \\
\hline \multicolumn{2}{|l|}{ Lymph node dissection } \\
\hline Yes & $123(75.9 \%)$ \\
\hline No & $39(24.1 \%)$ \\
\hline \multicolumn{2}{|l|}{ Removed lymph node } \\
\hline Mean \pm SD (range) & $8.42 \pm 5.45(1-32)$ \\
\hline
\end{tabular}

Table 1 (Continued)
Table 1 (Continued)

\begin{tabular}{lc}
\hline Features & Data \\
\hline Positive lymph node & \\
Mean \pm SD (range) & $2.47 \pm 2.09(1-11)$ \\
LND & $25(11.1-58.8)$ \\
Median (IQR) & \\
Bilateral positive lymph node & $21(17.1 \%)$ \\
Yes & $102(82.9 \%)$ \\
No & \\
MFI (months) & $110(67.9 \%)$ \\
$<12$ & $19(11.7 \%)$ \\
$12-24$ & $10(6.2 \%)$ \\
$24-36$ & $9(5.6 \%)$ \\
$36-48$ & $8(4.9 \%)$ \\
$48-60$ & $6(3.7 \%)$ \\
$\geq 60$ &
\end{tabular}

IQR, interquartile range; CT, computer tomography; MRI, magnetic resonance imaging; GP, gemcitabine and cisplatin; Gemox, gemcitabine and oxaliplatin; TS, paclitaxel and tiggio; M-VAC, methotrexate; vinblastine; doxorubicin; and cisplatin; TP, paclitaxel and cisplatin; TC, paclitaxel and carboplatin; GA, gemcitabine and epirubicin; GTC, gemcitabine; paclitaxe and cisplatin. LVI, lymphovascular invasion. LND, Lymph node density; SD, standard deviation; MFI, metastasis-free interval.

Since the 1990s, minimally invasive surgery, represented by laparoscopy, has begun to spread. However, two studies published in the New England Fournal of Medicine in 2018 indicate that survival rate and no recurrence rate were significantly better in the open group than in the minimally invasive group $(10,11)$. Similarly, our study corroborated that open surgery is an independent favorable factor for CSS and OS. Some scholars believe that laparoscopic surgery needs to fill the abdominal cavity with carbon dioxide when establishing an artificial pneumoperitoneum, which will promote the proliferation and metastasis of cancer cells (12).

Infiltration of tumor cells into blood vessels or lymphatic vessels is an important step in tumor transmission because these pathways provide access to distant organs (13). Similar to previous studies $(13,14)$, ours proved that positive LVI is 
Table 2 The multivariate analysis of metastasis-free interval

\begin{tabular}{|c|c|c|c|c|}
\hline Variable & Category & $\mathrm{HR}$ & $95 \% \mathrm{Cl}$ & $P$ value \\
\hline Pathological stage & PTa-2 vs. РT3-4 & 2.08 & $1.43-3.02$ & $<0.001$ \\
\hline Adenocarcinoma & Yes $=1, \mathrm{No}=0$ & 1.49 & $1.00-2.20$ & 0.048 \\
\hline Margin status & Positive $=1$, Negative $=2$ & 1.99 & $1.30-3.05$ & 0.002 \\
\hline
\end{tabular}

$\mathrm{HR}$, hazard ratios.

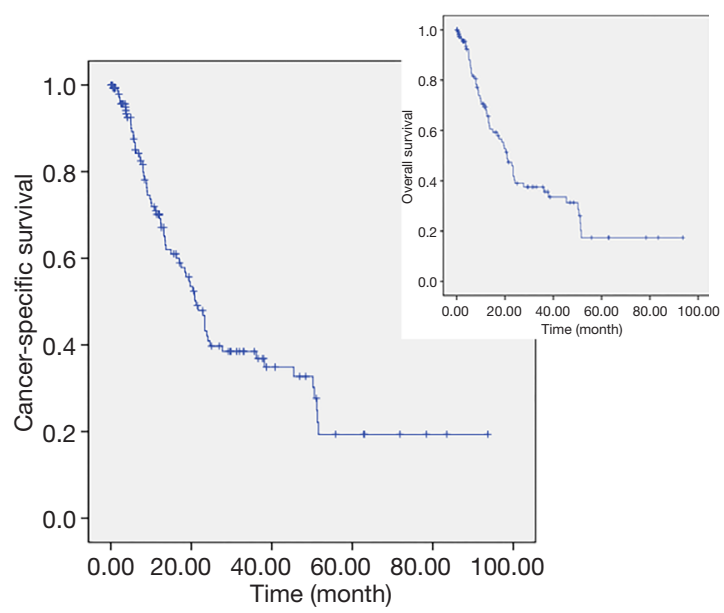

Figure 1 The CSS and OS rates of the metastatic bladder cancer patients assessed through Kaplan-Meier curves. CSS, cancerspecific survival; OS, overall survival.

an independent factor of poor prognosis for OS. However, the prognosis and clinical application of LVI are still controversial and further research is needed to prove the practical value of LVI in clinical decision-making.

Resembling previous studies $(7,15)$, our study indicated that liver metastasis is a disadvantage for prognosis. This may be explained by the loss of general immune infiltration accompanied by the loss of PD-1 and PD-L1 on immune cells commonly in liver metastases (57\%) (16). In addition, our study demonstrated that patients with local recurrence were more prone to lymph node and visceral metastasis, which affected the patients' prognoses.

Surprisingly, we found that the risk of visceral metastasis in pT4 was higher than that in pT3, but the risk of death in pT4 was lower than that in pT3. We believed that this may be due to the limited effect of metastasectomy or chemoradiation, and that some patients did not even undergo relevant treatment after metastasis. On the other hand, parts of metastases in
pT4 were limited in locality and were treated with RC. Therefore, the prognosis of patients with pT4 is highly variable. Although $56 \%$ of patients die of metastatic disease within 2 years after surgery, $32 \%$ of patients have no disease recurrence within 10 years after surgery (13). Consequently, subgroup analysis of pT4 patients ensued. The estimated CSS rates (SE) at 1 year, 3 years, and 5 years were $88 \%(6 \%), 50.6 \%(8.2 \%)$, and $24 \%(8.5 \%)$, severally; and this result was similar to that in a previous study (17). In a multivariate analysis, multifocality of primary tumors, margin-positiveness, local recurrence, and liver metastasis were detrimental to CSS, while lateral wall and local treatments of metastases were beneficial to CSS. The prognosis of female patients was worse than that of male patients, but the difference was not statistically significant $(\mathrm{P}=0.337)$, which is probably due to the small sample size (only 8 female cases).

Similar to some previous studies $(15,18)$, patients with positive margins had a worse prognosis. Positive margins may be attributed to immature surgical techniques, inappropriate specimen handling or processing process, inaccurate pathological assessment and inadequate dissection extent; while extensive exfoliation of soft tissue around the bladder may result in negative margins (13).

Furthermore, our study also found that OS was correlated with the age at which patients were transferred. The risk of death for older-than-63 patients was 1.87 times higher than that of their younger-than-63 counterparts $(\mathrm{P}=0.039)$. We believe this is a result of the late onset of bladder cancer and the natural lifespan of human beings.

Previous studies showed that perioperative chemotherapy and RC can significantly improve the survival outcomes of patients $(19,20)$. However, our study did not certify that the number of lymph nodes removed, the number of positive lymph nodes, or LND were associated with the prognosis of patients. We presumed that it was caused by insufficient lymph node dissection and visceral metastasis. Besides, the risk of LNM, a disadvantage of CSS and OS in a univariate 
Table 3 The multivariate analysis of cancer-specific survival and overall survival

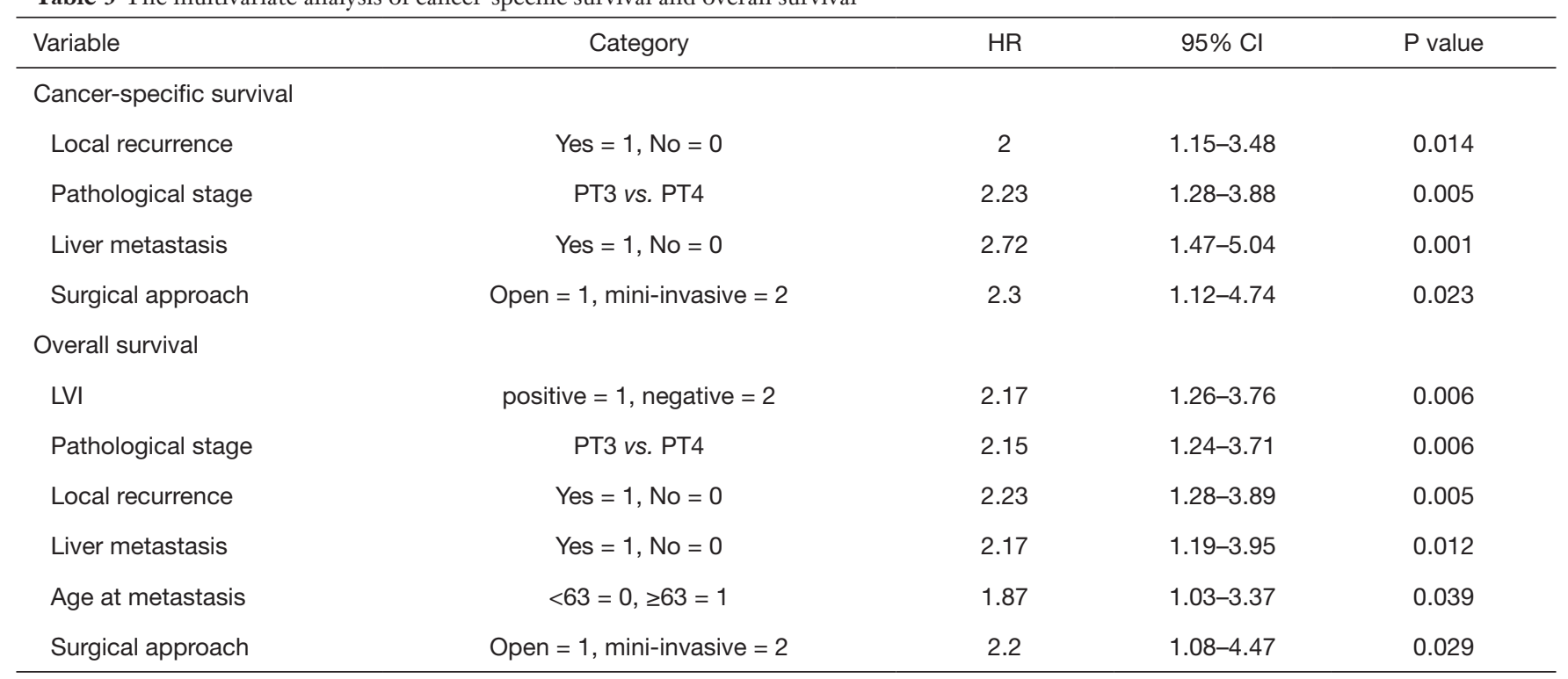

LVI, lymphovascular invasion.

analysis, was higher in MIBC than that in NMIBC. Therefore, we believed that pelvic lymphadenectomy was an important part of RC.

Some studies have shown that there is a disconnect between clinical trials and real-world treatment, which lacks in the standard 2-line treatment $(21,22)$. Similarly, our study found that only $21.0 \%$ of patients received adjuvant chemotherapy, and $24.1 \%$ of patients chose postmetastatic chemotherapy. Gemcitabine and cisplatin are the most commonly used and second-line chemotherapy is uncommon. Additionally, the beneficial effect of neoadjuvant chemotherapy (NAC) on survival was established by level 1 evidence (23). However, mere 1.4-11\% patients undergoing RC received NAC (24). Similarly, only 2 patients received NAC in our study. Interestingly, the survival advantage of NAC before RC remains controversial in current real-world practice (25).

There are some limitations in this study. First of all, the inherent limitations of retrospective studies are inevitable; Second, although we have found features that contribute to the stratification of prognosis in patients with MBC, we do not recommend discontinuation of adjuvant therapy and post-metastatic adjuvant therapy in patients with MBC. Because only a few patients receive postoperative chemotherapy in our study, the role of postoperative chemotherapy remains controversial. Third, surgery can be considered if necessary, but we cannot make relevant conclusions. In a subgroup analysis of pT4, we found that local treatment of metastases, including surgery, can improve patients' CSS. At last, the LNM rate of pT3 is higher than that of $\mathrm{pT} 4$, while the risk of visceral metastasis of pT4 is higher than that of pT3.Further studies are needed to investigate the relationship and mechanism between them.

\section{Conclusions}

Our study suggests that smoking history, positive margins, and pT3 or more advanced tumors in patients with $\mathrm{MBC}$ are more likely to be connected with metastasis. Besides, patients with minimally invasive surgery, local recurrence, and liver metastases are at greater risk of death from bladder cancer; Additionally, we should try to avoid the disconnections between clinical trials and realistic treatment. Taken together, our study provides data support for optimal management of patients with $\mathrm{MBC}$ in current real-world practice in western China.

\section{Acknowledgments}

Funding: The study was supported by the 1.3 .5 project for disiplines of excellence, West China Hospital, Sichuan University (ZY2016104) and Pillar Program 
from Department of Science and Technology of Sichuan Province (2018SZ0219).

\section{Footnote}

Reporting Checklist: The authors have completed the STROBE reporting checklist. Available at http://dx.doi. org/10.21037/tcr-20-737.

Data Sharing Statement: Available at http://dx.doi. org/10.21037/tcr-20-737.

Conflicts of Interest: All authors have completed the ICMJE uniform disclosure form (available at http://dx.doi. org/10.21037/tcr-20-737). The authors have no conflicts of interest to declare.

Ethical Statement: The authors are accountable for all aspects of the work in ensuring that questions related to the accuracy or integrity of any part of the work are appropriately investigated and resolved. The study was conducted in accordance with the Declaration of Helsinki (as revised in 2013). The study and disclaimer of informed consent were approved by the West China Hospital of Sichuan University Biomedical Research Ethics Committee (No. 2020366).

Open Access Statement: This is an Open Access article distributed in accordance with the Creative Commons Attribution-NonCommercial-NoDerivs 4.0 International License (CC BY-NC-ND 4.0), which permits the noncommercial replication and distribution of the article with the strict proviso that no changes or edits are made and the original work is properly cited (including links to both the formal publication through the relevant DOI and the license). See: https://creativecommons.org/licenses/by-nc-nd/4.0/.

\section{References}

1. Bray F, Ferlay J, Soerjomataram I, et al. Global cancer statistics 2018: GLOBOCAN estimates of incidence and mortality worldwide for 36 cancers in 185 countries. CA Cancer J Clin 2018;68:394-424.

2. Han S, Zhang SW, Chen WQ, et al. Analysis of the status and trends of bladder cancer incidence in China. Oncology Progress 2013;11:89-95.

3. Witjes JA, Bruins M, Compérat E, et al. EAU Guidelines on Muscle-invasive and Metastatic Bladder Cancer. EAU
2018. Available online: http://uroweb.org/guideline/ bladder-cancer-muscle-invasive-and-metastatic/\#11

4. Klapheke A, Yap SA, Pan K, et al. Sociodemographic disparities in chemotherapy treatment and impact on survival among patients with metastatic bladder cancer. Urol Oncol 2018;36:308.e19-308.e25.

5. Xie J, Zhang XB, Wen J, et al. Comparison of clinicopathological features in metastatic upper tract urothelial carcinoma and urothelial bladder cancer. Int Urol Nephrol 2016;48:481-7.

6. Dong F, Shen Y, Gao F, et al. Prognostic value of sitespecific metastases and therapeutic roles of surgery for patients with metastatic bladder cancer: a population-based study. Cancer Manag Res 2017;9:611-26.

7. Shinagare AB, Ramaiya NH, Jagannathan JP, et al. Metastatic pattern of bladder cancer: correlation with the characteristics of the primary tumor. AJR Am J Roentgenol 2011;196:117.

8. Leber MF, Efferth T. Molecular principles of cancer invasion and metastasis. Int J Oncol 2009;34:881.

9. Sasaki Y, Oi H, Oyama T, et al. Non-muscle invasive bladder cancer with multiple bone metastasis without local invasion: a case report. Hinyokika Kiyo 2013;59:669-72.

10. Melamed A, Margul DJ, Chen L, et al. Survival after Minimally Invasive Radical Hysterectomy for Early-Stage Cervical Cancer. N Engl J Med 2018;379:1905-14.

11. Ramirez PT, Frumovitz M, Pareja R, et al. Minimally Invasive versus Abdominal Radical Hysterectomy for Cervical Cancer. N Engl J Med 2018;379:1895-904.

12. Mo X, Yang Y, Lai H, et al. Does carbon dioxide pneumoperitoneum enhance wound metastases following laparoscopic abdominal tumor surgery? A metaanalysis of 20 randomized control studies. Tumour Biol 2014;35:7351-9.

13. Tilki D, Svatek RS, Karakiewicz PI, et al. Characteristics and Outcomes of Patients With pT4 Urothelial Carcinoma at Radical Cystectomy: A Retrospective International Study of 583 Patients. J Urol 2010;183:87-93.

14. Quek ML, Stein JP, Nichols PW, et al. Prognostic significance of lymphovascular invasion of bladder cancer treated with radical cystectomy. J Urol 2005;174:103.

15. Bellmunt J, von der Maase H, Mead GM, et al.

Randomized phase III study comparing paclitaxel/ cisplatin/gemcitabine and gemcitabine/cisplatin in patients with locally advanced or metastatic urothelial cancer without prior systemic therapy: EORTC Intergroup Study 30987. J Clin Oncol 2012;30:1107-13.

16. Eckstein M, Sikic D, Strissel PL, et al. Evolution of PD-1 
and PD-L1 Gene and Protein Expression in Primary Tumors and Corresponding Liver Metastases of Metastatic Bladder Cancer. Eur Urol 2018;74:527-9.

17. Furukawa J, Miyake H, Hara I, et al. Clinical outcome of radical cystectomy for patients with pT4 bladder cancer. Int J Urol 2008;15:58.

18. Dotan ZA, Kavanagh K, Yossepowitch O, et al. Positive surgical margins in soft tissue following radical cystectomy for bladder cancer and cancer specific survival. J Urol 2007;178:2308.

19. Zargar-Shoshtari K, Zargar H, Lotan Y, et al. A MultiInstitutional Analysis of Outcomes of Patients with Clinically Node Positive Urothelial Bladder Cancer Treated with Induction Chemotherapy and Radical Cystectomy. J Urol 2016;195:53-9.

20. Lucca I, Rouprêt M, Kluth L, et al. Adjuvant cisplatinbased combined chemotherapy for lymph node (LN)positive urothelial carcinoma of the bladder (UCB) after radical cystectomy (RC): a retrospective international study of >1500 patients. BJU Int 2015;115:722-7.

Cite this article as: Feng D, Bai Y, Yang Y, Han P, Wei W. Clinicopathological characteristics and treatment outcomes of 162 Chinese patients with metastatic bladder cancer: results from a tertiary teaching hospital. Transl Cancer Res 2020;9(8):4870-4878. doi: 10.21037/tcr-20-737
21. Galsky MD, Pal SK, Lin SW, et al. Real-World Effectiveness of Chemotherapy in Elderly Patients With Metastatic Bladder Cancer in the United States. Bladder Cancer 2018;4:227-38.

22. Laurent M, Brureau L, Demery ME, et al. Early chemotherapy discontinuation and mortality in older patients with metastatic bladder cancer: The AGEVIM multicenter cohort study. Urol Oncol 2017;35:34.e9-34.e16.

23. Grossman HB, Natale RB, Tangen CM, et al. Neoadjuvant chemotherapy plus cystectomy compared with cystectomy alone for locally advanced bladder cancer. N Engl J Med 2003;349:859-66.

24. Porter MP, Kerrigan MC, Donato BM, et al. Patterns of use of systemic chemotherapy for Medicare beneficiaries with urothelial bladder cancer. Urol Oncol 2011;29:252-8.

25. Hanna N, Trinh QD, Seisen T, et al. Effectiveness of Neoadjuvant Chemotherapy for Muscle-invasive Bladder Cancer in the Current Real World Setting in the USA. Eur Urol Oncol 2018;1:83-90. 
Supplementary

Table S1 Factors associated with LNM

\begin{tabular}{|c|c|c|c|c|c|c|c|}
\hline Variables & Number & LNM (\%) & $\chi^{2}$ value & $P$ value & OR & $95 \% \mathrm{Cl}$ & Cramer's V ( $P$ value) \\
\hline NMIBC & 11 & 9.10 & 9.547 & 0.002 & 16.03 & $2.00-128.556$ & $\mathrm{Phi}=0.268(0.001)$ \\
\hline MIBC & 151 & 61.60 & & & & & \\
\hline PT2 & 28 & 46.40 & 12.089 & 0.002 & & & $0.283(0.002)$ \\
\hline РТ3 & 60 & 78.30 & & & & & \\
\hline PT4 & 63 & 52.40 & & & & & \\
\hline РT2 vs. РT3 & & & 8.958 & 0.003 & 4.17 & $1.59-10.94$ & Phi=0.32 (0.003) \\
\hline PT2 vs. PT4 & & & 0.275 & 0.6 & & & Phi=0.055 (0.6) \\
\hline PT3 vs. PT4 & & & 9.103 & 0.003 & 0.3 & $0.14-0.67$ & $\mathrm{Phi}=0.272(0.004)$ \\
\hline Low grade & 10 & 50.00 & 0.04 & 0.84 & 1.41 & $0.39-5.09$ & $0.042(0.596)$ \\
\hline High grade & 152 & 58.60 & & & & & \\
\hline Trigone & 72 & 59.70 & 0.153 & 0.7 & & & \\
\hline Local recurrence & 56 & 69.60 & 4.743 & 0.03 & 2.13 & $1.07-4.22$ & $0.17(0.03)$ \\
\hline No Local recurrence & 106 & 51.90 & & & & & \\
\hline Lymph node dissection & 123 & 62.60 & 4.394 & 0.04 & 2.17 & $1.04-4.50$ & $0.17(0.04)$ \\
\hline No lymph node dissection & 39 & 43.60 & & & & & \\
\hline
\end{tabular}

LNM, Iymph node metastasis; OR, odds ratio; NMIBC, non-muscle invasive bladder cancer; MIBC, muscle invasive bladder. 
Table S2 Factors associated with visceral metastasis

\begin{tabular}{|c|c|c|c|c|c|c|c|}
\hline Variable & Number & $\begin{array}{c}\text { Visceral } \\
\text { metastasis (\%) }\end{array}$ & $\chi^{2}$ value & $P$ value & OR & $95 \% \mathrm{Cl}$ & $\begin{array}{l}\text { Cramer's V } \\
\text { v (P value) }\end{array}$ \\
\hline PT2 & 28 & 89.30 & 6.447 & 0.03 & & & $0.204(0.037)$ \\
\hline PT3 & 60 & 83.30 & & & & & \\
\hline PT4 & 63 & 96.80 & & & & & \\
\hline PT2 vs. РT3 & & & & 0.68 & & & \\
\hline PT2 vs. PT4 & & & & 0.17 & & & \\
\hline PT3 vs. РT4 & & & 6.354 & 0.012 & 6.1 & $1.28-29.13$ & $0.23(0.012)$ \\
\hline Local recurrence & 56 & 98.20 & 5.69 & 0.02 & 8.37 & $1.07-65.41$ & $0.19(0.02)$ \\
\hline No local recurrence & 106 & 86.80 & & & & & \\
\hline Lymph node metastasis & 94 & 84 & 11.958 & 0.001 & & & $0.27(0.001)$ \\
\hline No lymph node metastasis & 68 & 100 & & & & & \\
\hline Lymph node dissection & 123 & 88 & 3.89 & 0.049 & & & $0.18(0.022)$ \\
\hline No lymph node dissection & 39 & 100 & & & & & \\
\hline \multicolumn{8}{|l|}{ Bone metastasis } \\
\hline PT2 & 28 & 35.70 & 6.422 & 0.04 & & & $0.21(0.04)$ \\
\hline PT3 & 60 & 23.30 & & & & & \\
\hline PT4 & 63 & 12.70 & & & & & \\
\hline PT2 vs. РT3 & & & & 0.22 & & & \\
\hline PT2 vs. PT4 & & & 6.471 & 0.01 & 0.26 & $0.09-0.76$ & $0.27(0.01)$ \\
\hline PT3 vs. PT4 & & & & 0.12 & & & \\
\hline \multicolumn{8}{|l|}{ Liver metastasis } \\
\hline PT2 & 28 & 42.90 & 8.789 & 0.01 & & & $0.241(0.01)$ \\
\hline PT3 & 60 & 25.00 & & & & & \\
\hline PT4 & 63 & 14.30 & & & & & \\
\hline PT2 vs. РT3 & & & & 0.09 & & & \\
\hline PT2 vs. PT4 & & & 8.914 & 0.003 & 0.22 & $0.08-0.62$ & $0.31(0.003)$ \\
\hline PT3 vs. PT4 & & & & 0.13 & & & \\
\hline \multicolumn{8}{|l|}{ Lymph node metastasis } \\
\hline \multicolumn{8}{|l|}{ LVI } \\
\hline 1 & 69 & 18.80 & 6.066 & 0.048 & & & $0.203(0.048)$ \\
\hline 2 & 44 & 36.40 & & & & & \\
\hline 3 & 34 & 38.20 & & & & & \\
\hline 1 vs. 2 & & & 4.324 & 0.04 & 0.41 & $0.172-0.961$ & $0.20(0.038)$ \\
\hline 1 vs. 3 & & & 4.54 & 0.03 & 0.375 & $0.15-0.94$ & $0.21(0.03)$ \\
\hline 2 vs. 3 & & & & 0.865 & & & \\
\hline \multicolumn{8}{|l|}{ Local recurrence } \\
\hline 1 & & 23.2 & 13.244 & 0.001 & & & $0.3(0.001)$ \\
\hline 2 & & 43.2 & & & & & \\
\hline 3 & & 58.8 & & & & & \\
\hline 1 vs. 2 & & & 5.023 & 0.03 & 0.4 & $0.18-0.90$ & $0.211(0.03)$ \\
\hline 1 vs. 3 & & & 12.722 & $<0.001$ & 4.73 & $1.96-11.44$ & $0.35(0.000)$ \\
\hline 2 vs. 3 & & & & 0.17 & & & \\
\hline \multicolumn{8}{|l|}{ Lymph node metastasis } \\
\hline 1 & & 36.20 & 20.212 & $P<0.001$ & & & $0.371(<0.001)$ \\
\hline 2 & & 59.10 & & & & & \\
\hline 3 & & 82.40 & & & & & \\
\hline 1 vs. 2 & & & 5.669 & 0.017 & 2.542 & $1.17-5.523$ & $0.224(0.017)$ \\
\hline 1 vs. 3 & & & 19.396 & $P<0.001$ & 8.213 & $2.994-22.532$ & $0.434(<0.001)$ \\
\hline 2 vs. 3 & & & 4.872 & 0.027 & 3.231 & $1.111-9.391$ & $0.25(0.027)$ \\
\hline
\end{tabular}

LVI, lymphovascular invasion. 